\title{
A STUDY OF WIRELESS LAN BASED WORKING AREA ESTIMATION
}

\author{
Soungho CHAE \\ Kajima Technical Research Institute, Tokyo, JAPAN \\ chae@kajima.com \\ Takahiro NAKAMURA \\ Kajima Technical Research Institute, Tokyo, JAPAN \\ nakamurt@kajima.com
}

\begin{abstract}
A wireless LAN (local area network) was proposed as a means of determining location at a construction site. The high prevalence of equipment and facilities was offered as an advantage compared to existing methods. An experiment was performed to collect RSSI (radio signal strength indications). From the results, variations were shown in RSSI from radio signal transmission conditions, and the application of wireless LAN was discussed.
\end{abstract}

KEYWORDS: location information, working area, wireless LAN, RSSI

\section{INTRODUCTION}

In site management, the importance of work measurement to improve productivity and safety generally reflects the methods of factory production control. Work performance is measured by analyzing working time, operations, and motion. However, on the construction site, because workers and equipment perform different tasks in given locations, it is difficult to ensure a system that will continually collect the performance data needed to analyze the work. Performance data has been collected from physical observations made by the supervisor; thus, it is impossible to understand worker concurrent performance simultaneously throughout the construction site.

Location information on workers and equipment is one of the important issues for evaluating work performance. A number of location detection systems using wireless devices, such as GPS, RFID, UWB, and ultrasonic, have been proposed, and the technical applicability to the construction site was developed. However, these systems are operated under a much more favorable atmosphere for measurement where constant data reception is expected. Furthermore, the devices used for the location system are an investment for the construction site.

In this study, the authors examined the factors relating to the location systems and adopted wireless LAN (local area network) technology. Wireless LAN is a popular communication technology involving mobile devices that transmit radio signals and access points that connect the mobile devices to a network. The access point converts radio waves to an RSSI (receive signal strength indication), which is a measurement of the power present with changes in distance from the mobile device. 


\section{Estimate of location using wireless LAN}

\subsection{Related works}

There are several algorithmic approaches to location tracking using radio signals from wireless LAN with the advances in mobile technology, and they have various degrees of precision and accuracy. The algorithm is typically based on the following methods: angle of arrival (AOA), cell identity (CI), time of arrival (TOA), time difference of arrival (TDOA), or radio signal strength indication (RSSI).

A number of systems have been proposed. RADAR (Bahl 2000) and WiPS (Teruaki 2005) are empirical signal strength-based systems for location and tracking of users inside buildings. MoteTrack (Konrad 2005) computes the location of mobile nodes using an RSSI from numerous beacon nodes. Commercialized products such as Ekahau (2009) and AirLocation (Yamazaki 2005) are also available.

In the construction area, there have been no reports that wireless LAN was used to detect the location of workers and equipment, but a number of studies on the possibility have been carried out. Hiam (2009) compared three different wireless devices in wireless LAN indoors. Amir (2008) tested a commercialized wireless LAN device as an indoor positioning tracking system.

\subsection{Concept of RSSI-based location system}

The authors aimed to achieve a location system that fulfills the following objectives and selected RSSI on the wireless LAN as the data for location estimation.

a) Saving of system calibration effort

At the construction site, the installed status of equipment is frequently exchanged in accordance with the work process. An algorithm is necessary for operating the system right after relocation of the equipment. The linear relationship between RSSI and distance is one approach.

b) Expanding of equipment selection flexibility

The distribution of radio transmitters to all workers involved in a task of all processes causes an increase in the overall cost of management. A reduction in the initial cost to install the equipment should be considered.

c) Minimization of external constraints

A system is required that can be used to determine location during all construction processes without a technical change. For example, GPS is good method to determine location outdoors, but the function is limited by the service area of satellites.

d) Ensuring of real-time extraction

The information about the work situation in real-time reduces the time to make improvements for the site manager. It is necessary to build a network for collecting the data used to continually calculate the location of each worker. 


\section{Application of RSSI to location estimation}

\subsection{Experiment overview}

The authors performed the RSSI data collecting experiment in order to develop the estimation model for the location system. The RSSI data was obtained from wireless LAN access points on the testing site. The experiment was conducted according to mock situations where workers and heavy equipment are moving on the real site.

The methods and purposes of the experiment are described below.

a) Comparison between RSSI and distance from the access point to mobile devices

Rate of RSSI decrease and variations in distance are verified, and the margin of error that occurs while estimating the position of mobile devices is calculated.

b) RSSI of fixing mobile devices around access points

The association of RSSI with the location of mobile devices installed around several access points on the site is determined.

c) RSSI of moving mobile devices around access points

The association of RSSI with location of mobile devices that moved around several access points on the site is determined.

d) Consideration of positioning with RSSI

From the results of the experiment, the characteristic features of RSSI in each situation are verified in terms of location estimation.

\subsection{Specifications of wireless LAN equipment}

The wireless LAN equipment used was composed of an access point that received radio signals and a tag that transmitted a radio signal as a mobile device. The operating frequency of the equipment was $2.4 \mathrm{GHz}$ (IEEE 802.11b). The tag had a power level of $13 \mathrm{dBm}$ and signals with intervals of $250 \mathrm{mmSeconds}$. Each access point sends the collected RSSI and tag identification number to a control computer via Ethernet cable. Table 1 shows the specifications of the wireless LAN equipment and Photo 1 shows the tag and access point used in the experiment.

Table 1: Specifications for the wireless LAN equipment

\begin{tabular}{|c|c|c|}
\hline & Frequency & 2.4GHz(IEEE802.11b) \\
\hline \multirow{6}{*}{ Tag } & size & $58 \times 41 \times 18 \mathrm{~mm}$ \\
\hline & Weight & $35 \mathrm{~g}$ \\
\hline & Signal-transmitting interval & $250 \mathrm{mms}$ \\
\hline & transmit power & $13 \mathrm{dBm}$ \\
\hline & Antenna gain & $1 \mathrm{~dB}$ \\
\hline & Model & Hitachi Airlocation $\|$ Tag-w \\
\hline \multirow{4}{*}{ Access point } & size & $120 \times 29 \times 103 \mathrm{~mm}$ \\
\hline & Weight & $280 \mathrm{~g}$ \\
\hline & Antenna gain & $2 \mathrm{~dB}$ \\
\hline & Model & Icominc. AP- 50W \\
\hline
\end{tabular}




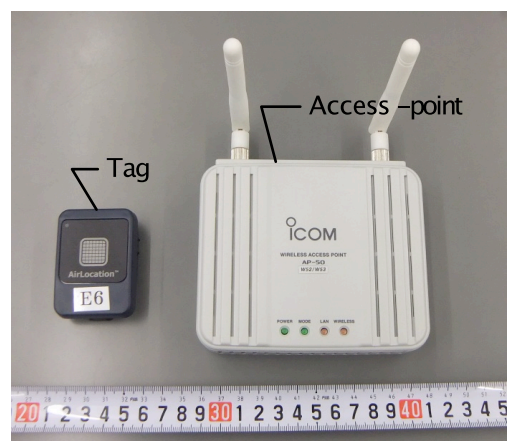

Photo 1: Tag and access point

The received signal power by the access point antenna in free space given the tag antenna distance transmitting a known amount of power is formulated by equation (1). (Harald 1946)

$$
P_{r}(d)=P_{t}+G_{t}+G_{r}-L_{d}
$$

Where

$P_{r}(d)=$ Receving power of antenna at distance $\mathrm{d}$ from transmitting anntena

$P_{t}=$ Transmitting power of antenna

$G_{t}=$ Antenna gain of transmitting antenna, $G_{r}=$ Antenna gain of receiving antenna

$L_{d}=20 \times \log _{10}\left(\frac{4 \times \pi \times d}{\lambda}\right), \lambda=$ wavelength

The graph of $P_{r}(d)$ on the tag and access point, which were used in the experiment is shown in Figure 1. The curve in Figure 1 has no variation with multi-path fading, path loss, and the signal-to-noise ratio of the antenna.

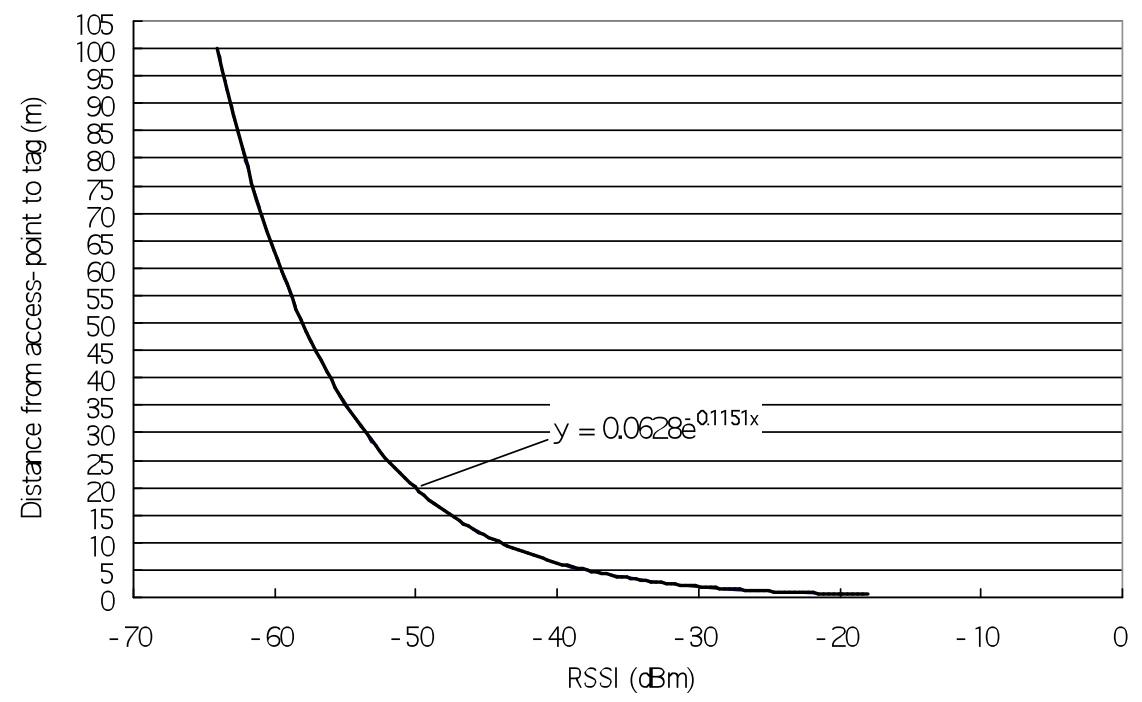

Figure 1: RSSI and distance from access point and tag in free space 


\subsection{Comparison between RSSI and distance from access point to tag}

Tags were placed at regular intervals from an access point, and the RSSI value was collected for about five minutes. A tag was installed at intervals of five meters at a height from the ground surface of about $1.8 \mathrm{~m}$ (Photo 2). The authors analyzed the relationship between RSSI and distance from the access point to the tag.

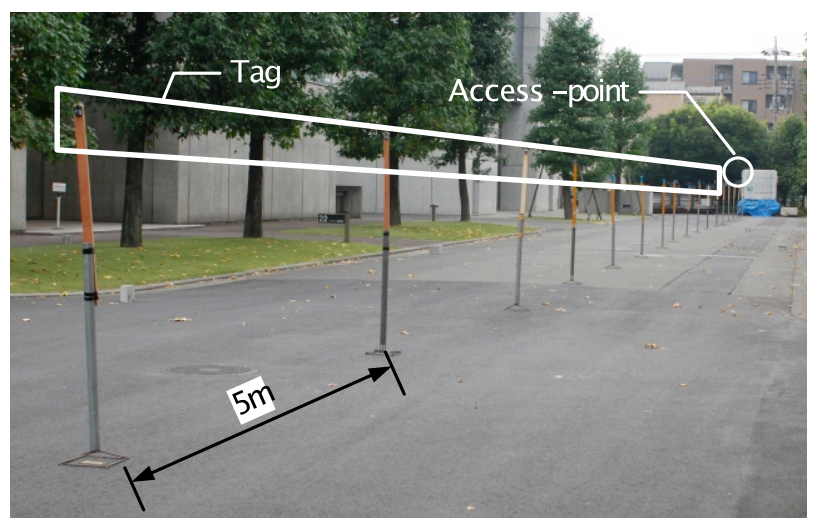

Photo 2: Tag and access point

The mean value and standard deviation of the collected RSSI data were calculated to confirm the reduced state of RSSI according to distance from the access point. Figure 2 shows the value and mean value of collected RSSI data from each access point. The highest mean value for RSSI was about $-50 \mathrm{dBm}$ for the tag installed $5 \mathrm{~m}$ from the access point. The tag installed $40 \mathrm{~m}$ from the access point has the smallest mean value for RSSI at about $-72 \mathrm{dBm}$, which is $5 \mathrm{dBm}$ lower than the tag installed at $100 \mathrm{~m}$. The standard deviation of each tag was from 0.9 $\mathrm{dBm}$ to $1.6 \mathrm{dBm}$, but the RSSI values that were abnormally lower than the mean value were collected intermittently. The result decreased by about $10 \mathrm{dBm}$ compared with the curve in free space. The difference between the actual and free space is influenced by several factors, such as ground-reflected wave, signal-to-noise ratio of the antenna, and other path loss.

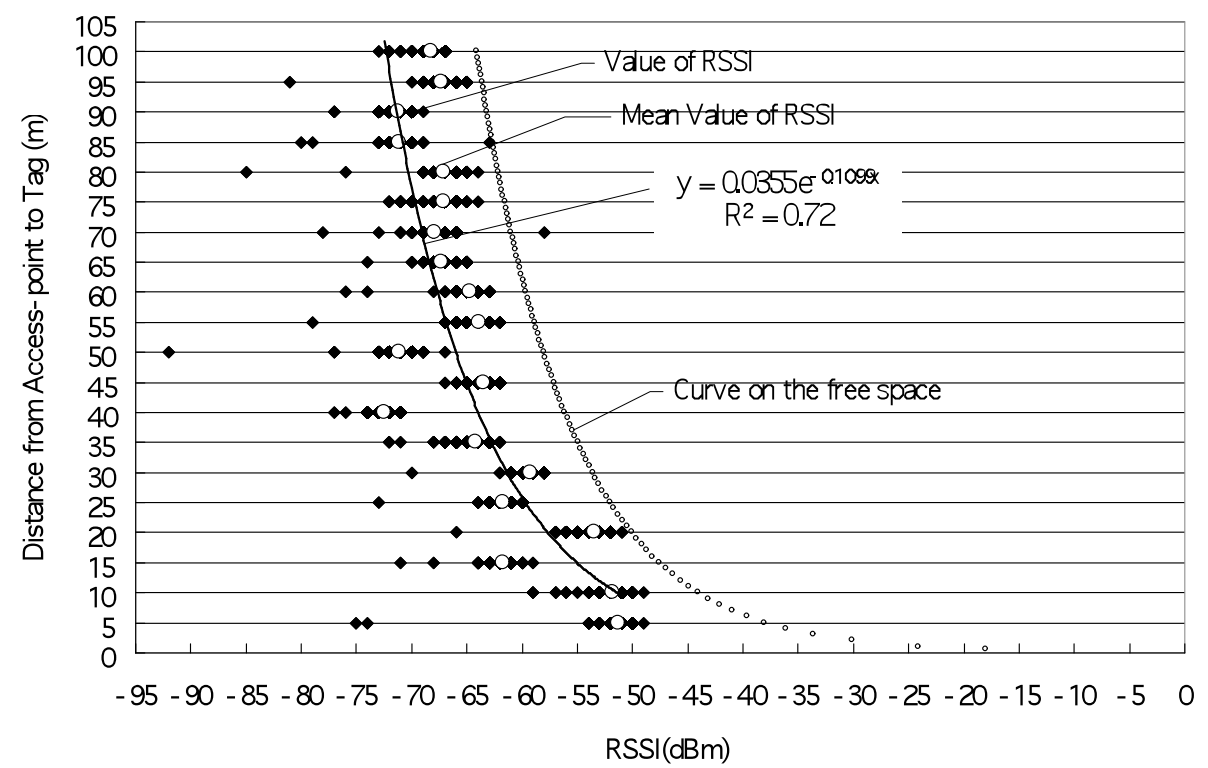

Figure 2: Value of RSSI from tags placed at regular intervals 
RSSI values are taken as input data and the exponential function was calculated by regression analysis. The exponential function was determined by equation (2) and the coefficient of determination $\left(R^{2}\right)$ was 0.72 .

$$
y=0.0355 e^{-0.1099 x}
$$

Where

$$
x \text { : RSSI value, } y \text { : distance from the access point to the tag }
$$

\subsection{RSSI of fixing tags around access points}

The authors installed 25 tags placed around 10 access points and collected the RSSI for each access point for about fifteen minutes. The height from the ground surface was about $1.8 \mathrm{~m}$. The relationship between RSSI and distance from the access point to the tag was analyzed. Figure 3 shows the installed positions of the tags and access points.

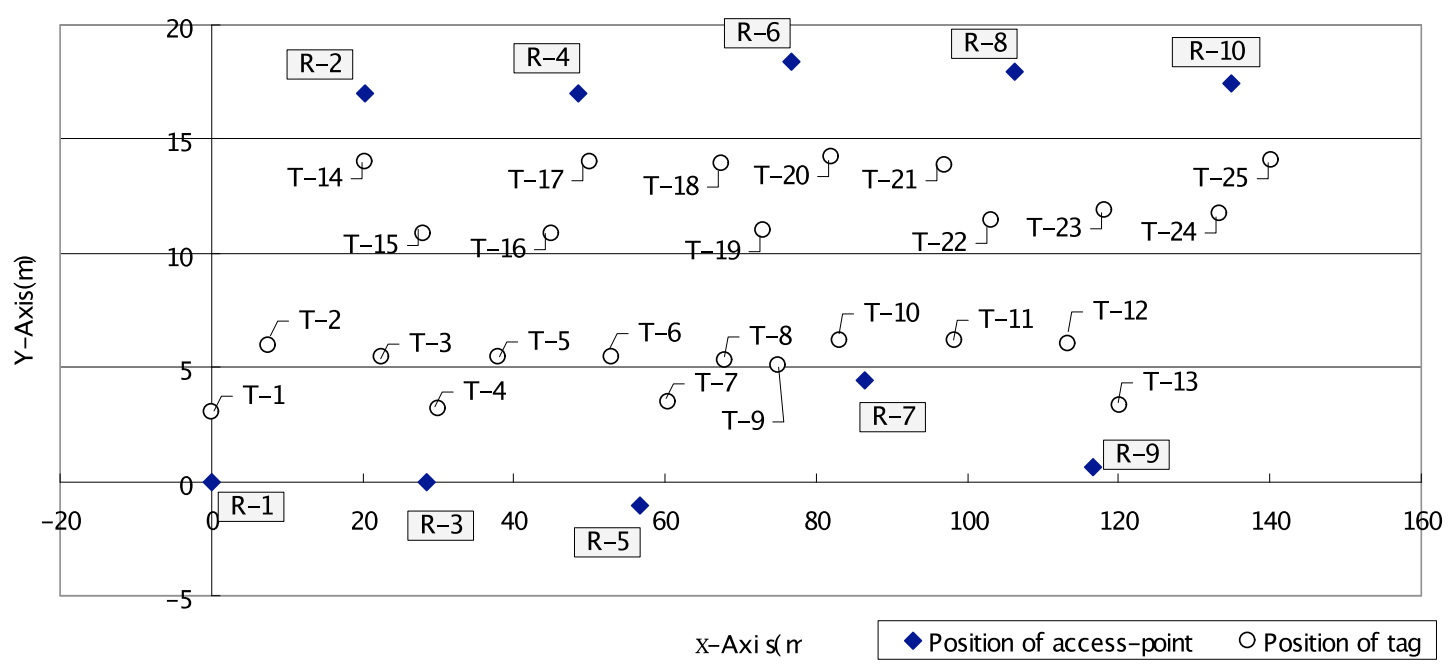

Figure 3: Installed positions of tags and access points

The mean value of each tag's RSSI data classified by distance from the access point was calculated. The variations in mean value of RSSI against distance were plotted in figure 4. The highest mean value was about $-42 \mathrm{dBm}$ for the tag installed $3 \mathrm{~m}$ from the access point. The tag installed $140 \mathrm{~m}$ from the access point had a mean value of about $-90 \mathrm{dBm}$. The standard deviation of each mean value was from $1.1 \mathrm{dBm}$ to $9.6 \mathrm{dBm}$.

The mean value of each tag's RSSI data are taken as input data, and the exponential function was calculated by regression analysis. The exponential function was determined by equation (2), and the coefficient of determination $\left(R^{2}\right)$ was 0.63 .

$$
y=0.1854 e^{-0.0761 x}
$$

Where

$x$ : mean value of RSSI, $y$ : distance from the access point to the 


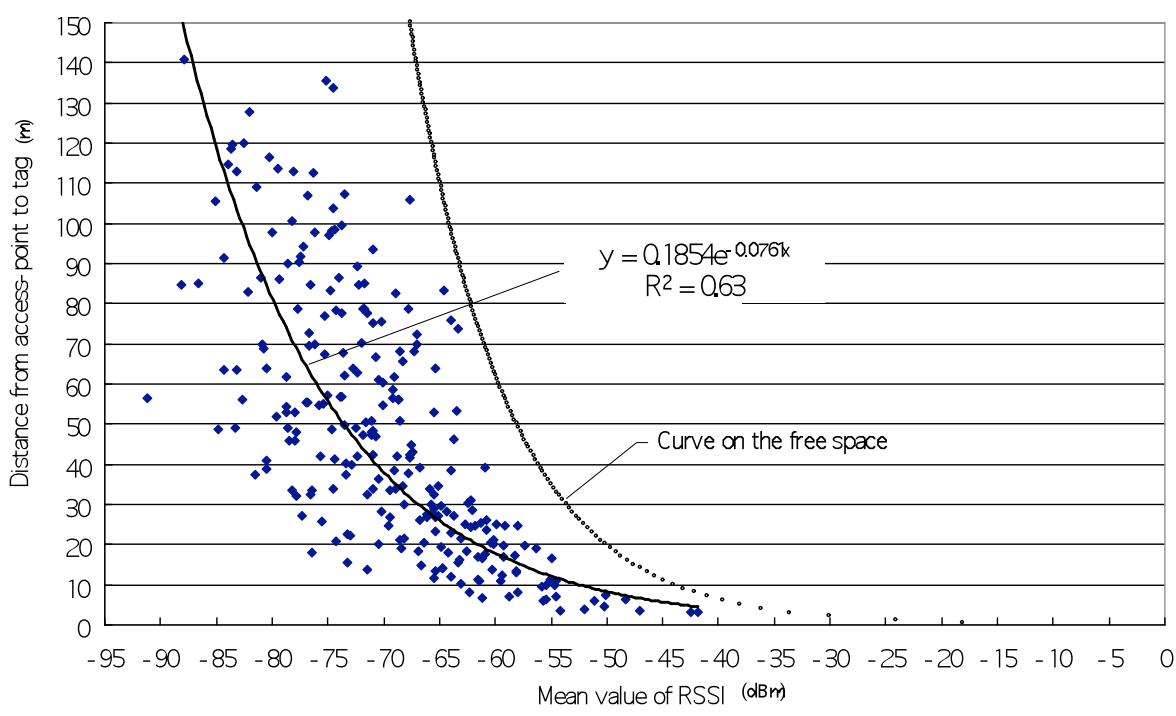

Figure 4: Mean value of RSSI from tags fixed around access points

\subsection{RSSI of moving tags around access points}

A forklift installed four tags at every corner for a total of ten access points, and the travel time around the entire site was about fifteen minutes. Moreover, actual position data for the forklift was collected by the RTK-GPS to calculate the distance from each access point. The relationship between RSSI and distance from the access point to the forklift was analyzed. Photo 3 shows the access points and the forklift. The driving course for the forklift and the position of the access points are represented in Figure 5.

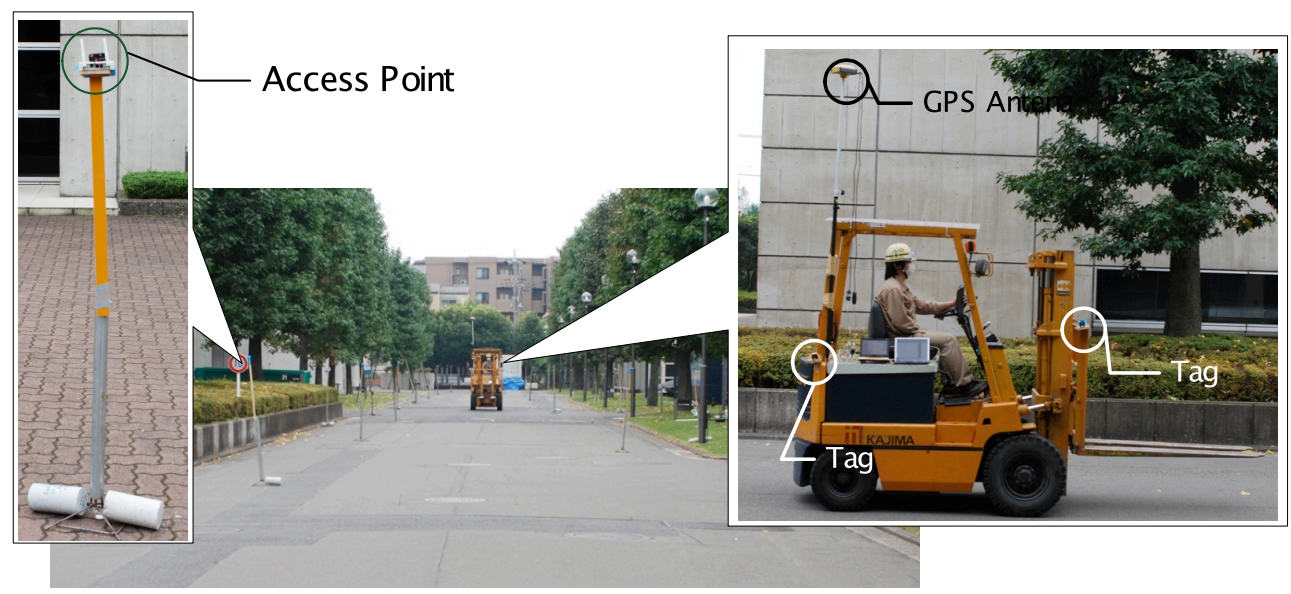

Photo 3: Access points and forklift

The mean value was calculated for the RSSI data from the four tags for each access point in a $10 \mathrm{~m}$ area classified by the distance from the access point. Figure 6 shows the mean value for collected RSSI data from ten access points. The highest mean value for RSSI was about -57 $\mathrm{dBm}$ in the assorted area within a range of $0 \mathrm{~m}$ to $10 \mathrm{~m}$ from the access point. The smallest mean value for RSSI at about $-85 \mathrm{dBm}$ was when the forklift travelled in an area of $111 \mathrm{~m}$ to $120 \mathrm{~m}$ from the access point. That was lower than the area over $120 \mathrm{~m}$ away from the access point. The standard deviation of each mean value was $4.0 \mathrm{dBm}$ to $7.8 \mathrm{dBm}$. 


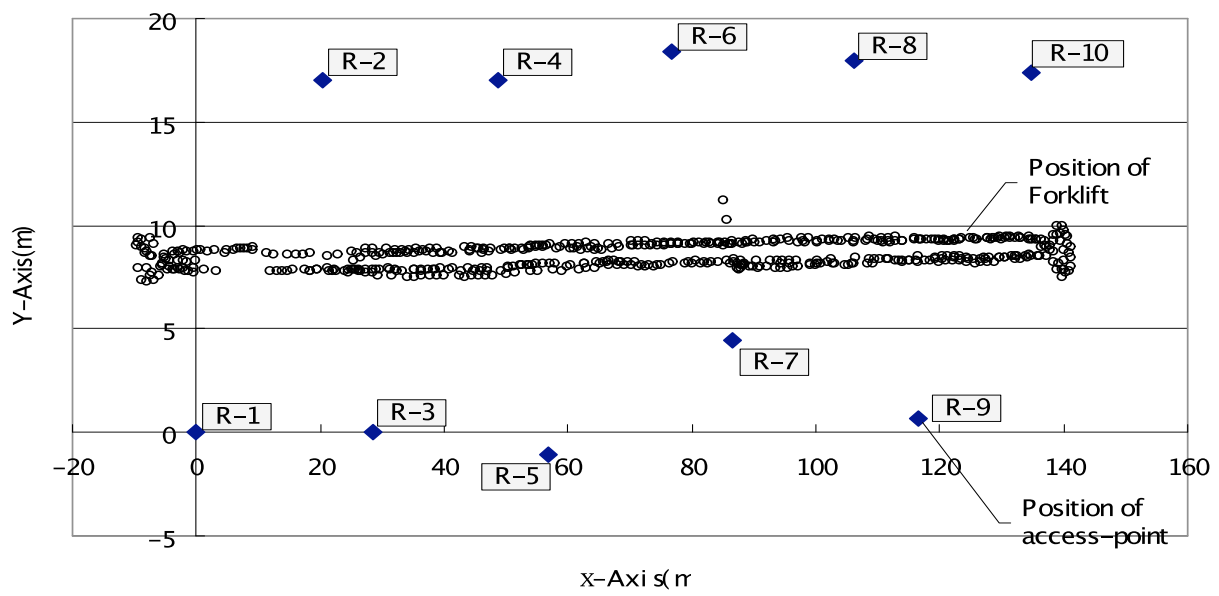

Figure 5: Driving course of forklift and position of access points

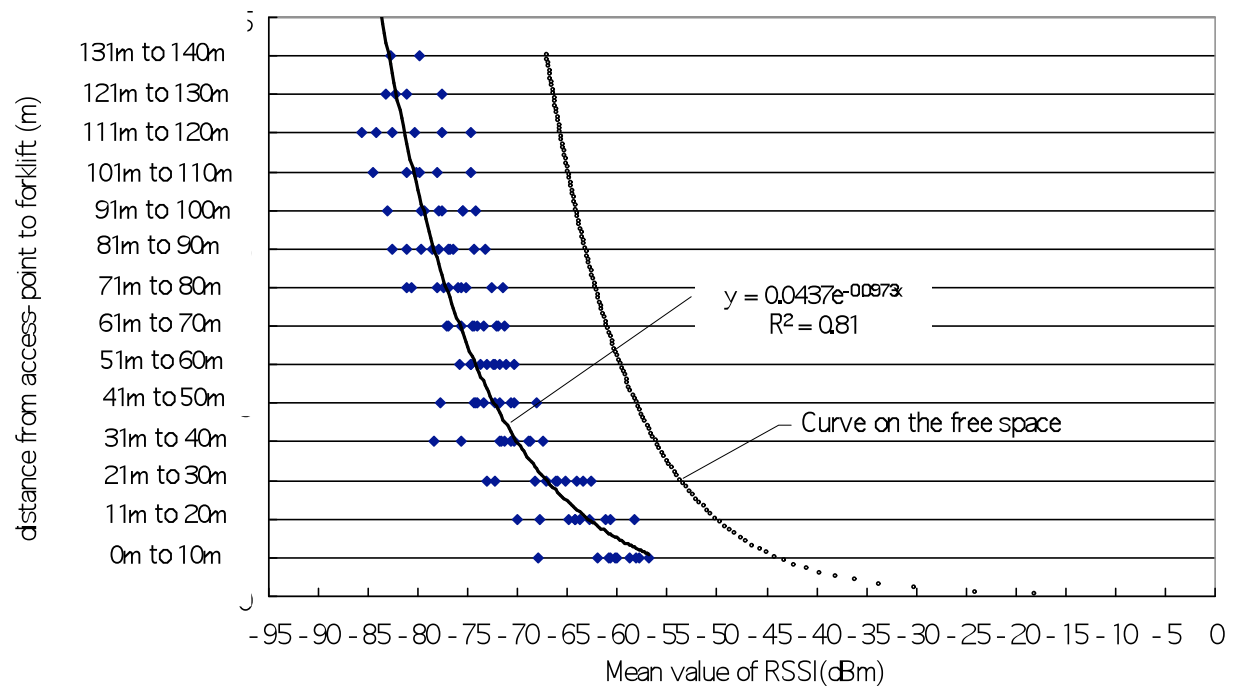

Figure 6: Mean value of RSSI from tags installed on forklift

The mean value of collected RSSI data from ten access points are taken as input data, and the exponential function was calculated by regression analysis. The exponential function was determined by equation (3), and the coefficient of determination $\left(R^{2}\right)$ was 0.81 .

$$
y=0.00437 e^{-0.0973 x}
$$

Where

$x$ : mean value of RSSI, $y$ : distance from access-point to tag

The mean values for the maximum and minimum RSSI differences for the four tags are shown in Table 2. The smallest mean value was $10.84 \mathrm{dBm}$ when the forklift was travelling within an area of $121 \mathrm{~m}$ to $130 \mathrm{~m}$ from an access point. The highest mean value was 13.59 $\mathrm{dBm}$ when the forklift was travelling within an area of $61 \mathrm{~m}$ to $70 \mathrm{~m}$ from an access point. The standard deviation was $3.96 \mathrm{dBm}$ to $5.45 \mathrm{dBm}$. 
Table 2: Mean value of maximum and minimum RSSI differences for four tags

\begin{tabular}{c|r|r|r}
\hline Distance from access-point to forklift $(\mathrm{m})$ & Mean value $(\mathrm{dBm})$ & Standard deviation(dBm & Number of sample \\
\hline Om to $10 \mathrm{~m}$ & 11.88 & 4.14 & 354 \\
\hline $11 \mathrm{~m}$ to $20 \mathrm{~m}$ & 12.03 & 4.76 & 852 \\
\hline $21 \mathrm{~m}$ to $30 \mathrm{~m}$ & 12.07 & 4.89 & 687 \\
\hline $31 \mathrm{~m}$ to $40 \mathrm{~m}$ & 11.78 & 4.61 & 603 \\
\hline $41 \mathrm{~m}$ to $50 \mathrm{~m}$ & 13.24 & 4.78 & 499 \\
\hline $51 \mathrm{~m}$ to $60 \mathrm{~m}$ & 13.05 & 5.38 & 501 \\
\hline $61 \mathrm{~m}$ to $70 \mathrm{~m}$ & 13.59 & 5.18 & 431 \\
\hline $71 \mathrm{~m}$ to $80 \mathrm{~m}$ & 13.01 & 4.93 & 337 \\
\hline $81 \mathrm{~m}$ to $90 \mathrm{~m}$ & 12.32 & 5.19 & 365 \\
\hline $91 \mathrm{~m}$ to $100 \mathrm{~m}$ & 13.09 & 5.13 & 251 \\
\hline $101 \mathrm{~m}$ to $110 \mathrm{~m}$ & 13.18 & 5.45 & 204 \\
\hline $111 \mathrm{~m}$ to $120 \mathrm{~m}$ & 11.25 & 4.64 & 190 \\
\hline $121 \mathrm{~m}$ to $130 \mathrm{~m}$ & 10.84 & 4.06 & 105 \\
\hline $131 \mathrm{~m}$ to $140 \mathrm{~m}$ & 11.37 & 3.96 & 78 \\
\hline
\end{tabular}

\subsection{Consideration of positioning with RSSI}

From the experiment results, we verified the following trends.

a) As the distance from the tag to the access point increases, the mean value of RSSI decreases, but the rate of decrease is not always proportional to the free space propagation model. The results of the distance estimation based on the free space propagation model require consideration of error rate, which includes variations in the RSSI.

b) Point positioning is conducted with distance from the access points to the tags, which is converted from RSSI. The accuracy of the determinate points depends on any errors in the distance value. Therefore, the minimum number of access points required to calculate the three-dimensional point coordinates is four. Figure 7 shows the variation in the difference between actual and calculated distance. Equation (3) was used to calculate the distance. The mean value of the distances was $7.13 \mathrm{~m}$, and the standard deviation was $31.01 \mathrm{~m}$.

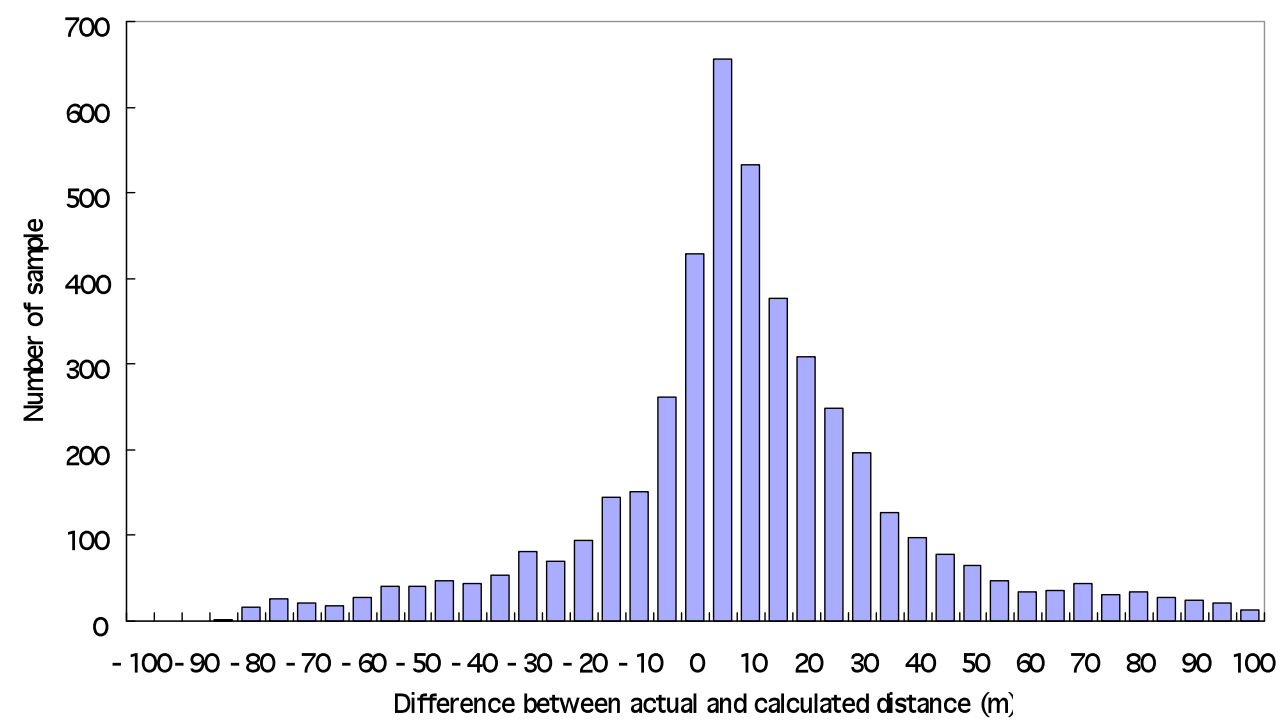

Figure 7: Variations in the differences between actual distance and calculated distance

c) The signal from the tags installed on the vehicles is affected by the body shielding. A stable value for RSSI from all tags installed on the vehicles cannot be expected. It is necessary to select the access points in installed locations with a high risk of being shielded by the vehicle's body when calculating the position. In addition, the frequency of $2.4 \mathrm{GHz}$ is easily absorbed by the human body, and the RSSI of tags on workers is expected to decrease. 
d) The tags used in this experiment were adjusted to transmit sustainable radio signals. When mobile devices, such as smart phones, use positioning, a method of cyclical signal transmission is necessary. Moreover, the preparation of battery power for signal transmission and cancellation of signal noise on the circuit board should be considered for practical use.

\section{CONCLUSIONS}

The authors proposed wireless LAN as a method of estimating the locations of workers and equipment on a construction site. The growth of devices with built in wireless LAN was described as the reason for simply using site management. Based on the experiment, the characteristic features were found of radio signals to the estimation of distance and error distribution to positioning.

\section{ACKNOWLEDGEMENT}

This work has been supported by a Grant-in-Aid for Scientific Research on Priority Areas (B) No.20360282 of the Japan Society for the Promotion of Science (JSPS).

\section{REFERENCES}

Bahl P., Padmanabhan VN., (2000) IEEE Infocom 2000: An in-building RF based user location and tracking system, Volume 2, 775-784

Konrad Lorincz, Matt Welsh., (2005) Proceedings of the international workshop on location and context-awareness: MoteTrack: A robust decentralized approach to RF-based location tracking

Ekahau, Inc.: http://www.ekahau.com/products/real-time-location-system/overview.html

Yamasaki R., Ogino A., Tamaki T., Uta T., Matsuzawa N.; Kato T., (2005) IEEE Wireless Communications and Networking Conference: TDOA Location System for IEEE 802.11b WLAN, Volume 4, 2338 - 2343

Harald T. Friis, (1946) Proceedings of the IRE and waves and electrons: A note on a simple transmission formula, 254-256

Teruaki K., Kenji H., Tsuneo N., (2005) Proc. International conference on pervasive systems and computing: Positioning technique of wireless LAN terminals using RSSI between terminals, $47-53$

Hiam M. K., Vineet R. K., (2009) Automation in construction: Evaluation of position tracking technologies for user localization in indoor construction environments, 444-457

Amir H. B., Zeeshan A., Chimat J. A., Vineet R. K., (2008) Automation in construction: Ubiquitous location tracking for context-specific information delivery on construction site, 737-748 